\title{
Radio in the service of the Red Cross
}

$A$ radio medical service was started 35 years ago by the Netherlands Red Cross Society, whose review (No. 3, 1967) gives an outline of how this service operates. This is a striking example of Red Cross initiative replying to a genuine need by establishing a new service. It is now part and parcel of the country's medical service.

When a sailor falls ill at sea or is the victim of an accident he may require medical attention beyond that which the ship's officers can provide. The ship can call Radio Scheveningen and consult a Red Cross doctor over the air.

In view of the increasing number of calls, there are now two doctors attached to this service. At any time they respond to appeals for a wide variety of cases and consequently they must have special qualifications and knowledge on tropical diseases, limits to a ship's officer's medical ability, the medical equipment aboard ships of various nationalities, and disembarkation and hospitalization facilities in ports throughout the world.

There is always one of these doctors available at the coastal station where telegrams and radio calls are received from ships. Details are recorded, such as name, course, position, speed, the patient's condition and symptoms. These are conveyed to the doctor who immediately transmits advice or contacts the ship later if he has need to consult a specialist. He tells the vessel when to call back and sometimes telephones the shipping company or its medical adviser. He draws up a report and receives the typed transcription of the station's recording of the radio contact, which includes the ship's officer's description of the case.

Although the medical knowledge of a ship's officer, who has to deal with injuries and sicknesses which require his having had training courses in hospital, must not be underestimated, it is none the less true that for him too the radio medical service is an addi- 


\section{IN THE RED Cross WORLD}

tional resource on which he can rely and it is one which sailors appreciate highly. We would add that each case is followed up to the end and that even coastal traffic, although there is a Netherlands hospital-ship available, can nevertheless have recourse to the radio service.

This is an example of practical radio service. Another one was provided in 1945 when the first lists of French deportees released in Germany for repatriation via Switzerland were read out by Radio Geneva. Subsequently news broadcasts were made in many languages by Radio Inter-Croix-Rouge.

In the field of humanitarian principles and Conventions, the radio is today an important medium for dissemination. As mentioned in the latest issue of the review Youth it reaches the younger generations and offers them a means of working to spread the Red Cross ideal. ${ }^{1}$ Thus, for example, in the Upper Volta:

The radio is undoubtedly the most effective media for disseminating lessons on the Red Cross, its principles and the Geneva Conventions. The broadcasts reach the whole territory and even listeners in Dahomey, Togo, Niger and the Ivory Coast, who eagerly voice their appreciation and observations.

The active method is employed for this Red Cross instruction: variety shows by young people for young people. Naturally the whole population listens in and takes an interest. To arouse and maintain such interest, a wearisome enumeration of Red Cross principles and the contents of the Conventions would be far from successful. Explanations are intersected with songs, stories, anecdotes; small local details serve to illustrate and act as a lesson.

First-class, lively presentation is required. This presents difficulties and a selection has to be made among young speakers. Parents naturally have pleasure in hearing their children's voices on the radio and every Junior wants to become a speaker. The legitimate pride of parents, plus the emulation which exists among Juniors, results in a wide and appreciative audience for the Upper Volta Junior Red Cross broadcasts.

${ }^{1}$ See Youth, 1967, No. 2; League of Red Cross Societies, Geneva. 


\section{IN THE RED CROSS WORLD}

In conclusion, a word should be said about another important media, the Red Cross emergency radio communications system, which has already been brought to the notice of International Review readers. ${ }^{1}$

A fixed radio communications station has been installed in ICRC headquarters in Geneva. From this station messages can be sent over the air to delegations in distant countries. For example, the ICRC has been in permanent contact with the radio station it set up in the heart of the Yemeni desert, in 1963, at Uqhd, an important centre of operations.

In addition, effective radio communication is maintained with the mobile medical teams working in the North of the Yemen, thanks to the emergency network set up by the ICRC. These teams operate in places which are difficult of access, sometimes cut off from the world except for their liaison with other teams and a central station in Amara, which is permanently in contact with the ICRC in Geneva.

As mentioned in the circular they sent in January 1965 to all National Red Cross, Red Crescent and Red Lion and Sun Societies, the International Committee and the League considered that a radio station in Geneva, where the two International Institutions of the Red Cross have their headquarters, represented an important step forward towards a Red Cross world-wide radio communications network. Radio broadcasting opens up a new perspective for immediate relief to victims and the rapid allaying of anxiety. 1965.

${ }^{1}$ See International Review, August 1961, December 1964 and January 